\title{
INFLUÊNCIA DAS AÇÕES DO INTERCÂMBIO BRASIL X CANADÁ: RELATO DE EXPERIÊNCIA DO NÚCLEO DE ESTUDOS CANADENSES EM RONDÔNIA, UM AGENTE INTEGRADOR MULTICULTURAL
}

\author{
INFLUENCE OF SHARES OF EXCHANGE BRAZIL X CANADA: CORE CANADIAN \\ STUDIES OF RONDÔNIA, INTEGRATOR AGENT MULTICULTURAL
}

\author{
Pedro Paulo Almeida Martins ${ }^{1}$ \\ Miguel Nenevé ${ }^{2}$
}

RESUMO: O presente estudo buscou identificar de início a discussão da importância do $\mathrm{Nec}^{3}$ no contexto multicultural, levando em conta que esta entidade tem o papel de desenvolver e fortalecer as pesquisas e atividades de extensão por meio de intercâmbio de estudantes no meio acadêmico. Há inclusive uma diretriz impregnada que visa assim à promoção das atividades acadêmicas e sociais para integrar, disseminar e difundir a informação do Canadá e demais países no Brasil. Essa entidade por meio da Abecan ${ }^{4}$ possui uma parceria e convênio com a Embaixada do Canadá, com o intuito de incentivar as atividades acadêmicas e sociais estimulando os estudantes a desenvolverem projetos que promovam situações de aprendizagem, bem como situação de ensino de línguas estrangeiras em geral. Além da biblioteca, o departamento também disponibiliza aos acadêmicos e para a comunidade, cursos de diversas línguas estrangeiras. Hoje a situação do Nec está em fase de consolidação no estado de Rondônia, em consequência disso é tão vital que o NEC tem a função de como agente multicultural, continuar a motivar para formação da identidade cultural dessas nações.

Palavras- Chave: Núcleo de Estudos Canadenses. Agente Multicultural. Disseminar a informação.

\footnotetext{
I Bibliotecário Documentalista do Instituto Federal de Rondônia- IFRO. Acadêmico do curso Direito na Faculdade Católica de Rondônia- FCR e graduando em Ciências Sociais na Universidade Federal de Rondônia - UNIR, Porto Velho, Brasil; Pedro Paulo Almeida Martins, Bibliotecário, tecnólogo em Gestão pública, 4 titulações de pós-graduado: Especialista em Gestão Pública, metodologia do ensino superior em Língua Portuguesa, Biblioteconomia e MBA em Governança e Gestão Administrativa, , E-mail: pedropaulogestorpublico@gmail,com, currículo Lattes: http://lattes.cnpq.br/3951670487194507 Orcid: https://orcid.org/oooo-ooo2-3490-8784

${ }^{2}$ Professor Doutor da Universidade Federal de Rondônia - UNIR - Campus de Porto Velho. Doutor em Letras. Email: neneve@unir.br, lattes: http://buscatextual.cnpq.br/buscatextual/visualizacv.do?metodo=apresentar\&id=K4799rogY4 , Orcid: https://orcid.org/ooo² Associação Brasileira de Estudos Canadenses

o-0002-9792-II34

${ }^{3}$ Núcleo de Estudos Canadenses
} 


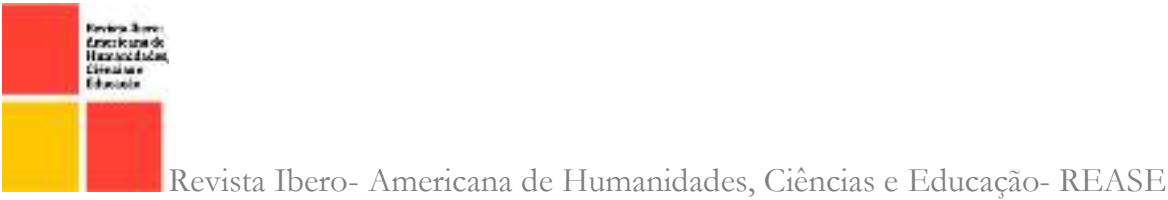

ABSTRACT: This study sought to identify the beginning of the discussion of the importance of $\mathrm{Nec}$ in multicultural context, taking into account that this entity has the role to develop and strengthen research and extension activities through exchange of students in the academic middle. There is even a well impregnated guideline aimed at promoting academic and social activities to integrate, disseminate and spread the Canadian information and other countries in Brazil. This entity through ABECAN has a partnership and agreement with the Canadian Embassy, in order to encourage academic and social activities encouraging students to develop projects that promote learning situations, as well as foreign languages in general education situation. Besides the library, the department also available to scholars and the community in various foreign languages courses. Today the situation $\mathrm{Nec}$ is in consolidation phase in the state of Rondonia, as a result is so vital that the NEC has the function of how multicultural continue to encourage training for the cultural identity of nations.

Keywords: Center for Canadian Studies. Multicultural agent. Disseminating information.

\section{INTRODUÇÃO}

O presente projeto de trabalho surgiu da motivação para o estudo do assunto da experiência de observação da vivência diária no grupo de Pesquisa e Extensão no período de 42 meses, neste trabalho, apresentaram-se muitas idealizações de projetos.

O NEC é composto pelo maior acervo de línguas estrangeiras de Rondônia (inglês, francês e espanhol) e pode atender toda a universidade (pesquisadores-doutor, mestrado, pós-graduação, graduação e comunidade) e até mesmo toda a comunidade. Para a construção das obras, podemos elencar três obras de fundamental importância para a construção da identidade e representação da população brasileira, além de obras clássicas: I) A identidade cultural pós-moderna de Stuart Hall 2) Homem cordial Autor: Sérgio Buarque de Holanda, 3) Angela Pryston e 4) Casa Grande \& Senzala, Gilberto Freyre, 5) Cultura de Raymond Williams e outros autores que contribuíram com esta pesquisa. A seguir, enfocaremos algumas das contribuições dessas obras e a chamada interpretação da análise e do conhecimento da composição cultural brasileira.

Esta entidade refere a identificar que multiculturalismo é uma prática constante na universidade por meio do NEC. Para tanto, o artigo está organizado com a seguinte estrutura: primeiramente destacou-se a busca pela compreensão do intercâmbio do NEC como agente que fomenta o multiculturalismo em uma perspectiva multicultural que interliga as nações por meio do intercâmbio e entre outras ações. Em seguida, apresenta-se uma breve contextualização dessa investigação através de vários autores, trazendo a 
importância dos Necs para o Brasil e para a propagação das culturas, na sequência, expõem os resultados desta e, finalizando, apresentam-se breves considerações.

\section{METODOLOGIA}

A metodologia empregada foi à pesquisa e revisão bibliográfica em fontes virtuais e impressa referentes aos autores acima citados, com isso houve também coleta de dados através de entrevistas e o resgate de documentos.

\section{O PAPEL DO NÚCLEO DE ESTUDOS CANADENSES: A IMPORTÂNCIA DO INTERCÂMBIO BRASIL/ CANADÁ PARA A PROMOÇÃO DO MULTICULTURALISMO}

No primeiro momento é interessante salientar que o NEC tem um papel importante e influente para pulverizar e firmar os laços políticos, econômicos, culturais e sociais do Brasil com o Canadá é extremamente saudável, prova disso é que atualmente no Brasil, possui II Necs distribuídos, em 2000 foi criado na região norte sendo o único. É importante ressaltar ser uma entidade, que tem o intuito de fomentar e semear os estudos e pesquisas que envolva tanto o Brasil como o Canadá.
De acordo com (BRANDÃO, 1996,p.3I), explica que: a atividade universitária de estudos, ensinar e pesquisar e, por causa disso, de levar a um aprofundamento intelectual, à conquista de novos horizontes do conhecimento e à criatividade, está intimamente vinculada ao desenvolvimento da cultura. A vida universitária é, ou deveria ser, o ambiente germinador, por excelência, da atividade cultural

No entanto, a Abecan com todos os NECS ao nível Brasil tem o papel conjunto de está em trabalho; promovendo, difundindo e disseminando o avanço dos estudos e pesquisas voltadas. Entretanto, se tratando de assuntos relacionados os aspectos culturais, econômicos, políticos, sociais que envolvam neste país, o Núcleo de Estudos canadenses está para dar o devido suporte através da biblioteca com o variado acervo de obras em inglês, Francês, espanhol e entre outras.

(ALMEIDA,2005,p.147) Já pensa que essa feição multidisciplinar assinalada pelo historiador caracterizará os estudos canadenses em as fase de internacionalização que ocorre ao longo dos anos 1970, quando pesquisadores de diferentes países passam a interessar- se pelas possibilidades de troca e de diálogo ensejadas pelos estudos canadenses. 


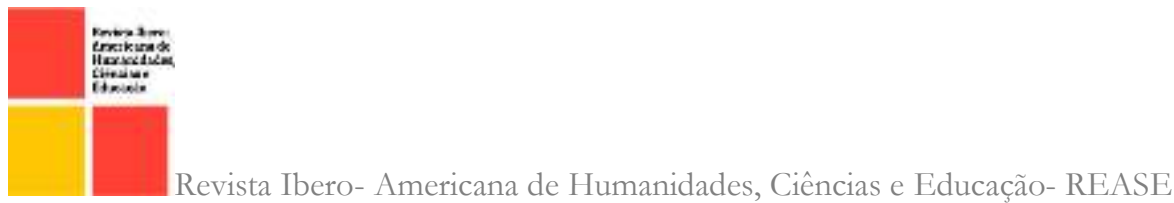

Em alínea com o contexto, podemos destacar que a educação é algo de prioridade para os canadenses, o Brasil não tem uma visão diferente, o Nec é uma ponte para interligar Brasil em relação ao Canadá por meio do intercâmbio, a instituição tem que propor condições para ficar mais ostensivo o apoio deste país, para isso deve-se aumentar e incentivar cada vez mais as pesquisa existente no Núcleo de Estudos canadenses de Porto Velho-Rondônia e apresentar resultados para cada vez mais, aumentar as parcerias e convênios. Contemporaneamente, levando num ponto de vista econômico a atualidade no Brasil dos jornais e meios de comunicação, demonstra que: num cenário nacional o comércio bilateral em 2012 foi de certa forma bem considerável, rendeu em negócios U\$ 6,1 bilhões, as transações Brasil/Canadá que ainda contínuo significativo, sendo que em 201 foi a marca de 6,6 bilhões. O Brasil possui muitas empresas canadenses em São Paulo e em outros estados em vários segmentos, cada dia assumi um cenário fixo nas relações entre os dois países. Mas um destaque em referência é a produção agrícola, este setor tem uma mera semelhança no desenvolvimento dos segmentos de produção de suas agriculturas tanto nos dois países supracitados anteriormente. Com o mercado prospero, a procura para o intercâmbio com destino ao Canadá, pelos brasileiros está cada vez mais frequente e crescente, sendo o país com a procura e destino daqueles que pretendem ingressar na faculdade e ampliar a fluência na língua inglesa e a outra segunda língua desejada que é o Francês.

Segundo dados da Revista Canadá/ Brasil (2013, p.18), em que afirma que nós últimos anos o número de alunos inscritos em cursos no País da América do Norte mais que triplicou. Segundo dados do Ministério de Cidadania e Imigração do Canadá, 687 brasileiros participaram de cursos com seis meses ou mais em 2003 enquanto em 2011 o número chegou a 2493.

Inclusive o Brasil está entre os dez países que mais enviam estudantes para o Canadá. O estado de Rondônia planta sua semente com a atuação do NEC. Por isso, entende-se que com essa crescente procura de estudantes em qualificação, acaba tornando um negócio que desperta muita importância para as agências especializadas em desenvolvimento educacional. Então é fácil entender que essa alta procura por intercâmbio e avanços nos estudos se dá pelo Canadá ser um país acolhedor às culturas e nacionalidades de outros países.

I.2 Recontexto do Multiculturalismo brasileiro e canandense como exemplo para o mundo 
O termo acolhedor identifica muito bem com o conceito transculturalismo, que melhor se adéqua pela forma do "Trans": ser uma partícula de ir além, em que, ir além da cultura. O termo cai bem, pela forma que o multiculturalismo permite acabar com toda forma de pensar e de ficar na apatia sem troca cultural. Já aborda:

[...] que não pretende fazer discussões voltada na área do conhecimento filosófico, pois não há possibilidade de diligir variantes e a que o então pósmodernismo vive da pluralidade, o autor também menciona que o pós modernismo, com a forma de cultura com reflexos bem submerso na superficialidade. (NENEVÉ, 2005, p.30)

Conforme consta na (Revista Brasil/ Canadá, 2013), as diretrizes do governo foram absorvidas na educação, nos meios de comunicação o resultado disso é um respeito percebido no dia-a-dia da população. "Para além das questões raciais, hoje também o respeito maior da diversidade sexual, à mulher, as religiões, às minorias”, o histórico dos países, favoreceu a absorção das políticas multiculturais. "O Canadá foi criado por três povos: índios, franceses e ingleses. Depois recebeu muitos modos de vida a respeitar o diferente." O interesse é que a proporção está coerente, se a política está funcionando o estado não chama-lhe a responsabilidade e é mais aberto. Então, "a comunidade se organiza em fóruns a monitorar" assim, conta o advogado Volney Campos dos Santos, autor do livro "Multiculturalismo canadense dos direitos constitucionais e a garantia de preservação e transmissão da cultura de origem”. Certamente consta na (Revista Brasil/ Canadá, 2013), que consoante o último Censo do IBGE, a população do país aumentou 5,9\% desde 2006-os imigrantes respondem por dois terços desse crescimento. Mais de 200 etnias estão representadas e mais de 200 línguas são faladas. Hoje, a taxa de imigração do Canadá é uma das maiores do mundo, esse mosaico é resultado da miscigenação dos colonizadores com os povos já presentes no território. De fato, o multiculturalismo, ao mesmo tempo, em que apresenta desafios e exige respeito, é uma oportunidade de buscar soluções criativas para o mundo moderno, não apenas nas relações sociais do dia-a- dia, mas também na consecução de negócios. Sob esse prisma, a diversidade é bastante enriquecedora no jargão popular:

Para a (REVISTA BRASIL/ CANADÁ, 2013, p.28), em que, tanto o Brasil como o Canadá vem investindo em pesquisas voltado a energia limpa de fontes que provem de recursos naturais para manter a um crescimento econômico sustentável. Já em zolo foi assinado um acordo Quadro Brasil/ Canadá para cooperação em Ciência, Tecnologia e inovação. Reunindo, pela primeira vez, no ano seguinte, em Otawa, o comitê conjunto, criado a partir do acordo. 
O Brasil é um país cosmopolita, hoje na maioria; respeita e entende as diferenças, hábitos e modos de diversos povos, como em certa região do Sul do país que tem colônias russas, inglesas e até bairros como é o caso em São Paulo de imigrantes japoneses, isso que é aceitar e dizer "não" ao preconceito. Possuímos diversas culturas que através de muitos movimentos por meios dos fluxos migratórios, facilita ao imigrante a procurar pelo Brasil para construir à vida e famílias, como é o caso dos imigrantes haitianos ${ }^{5}$ que procuram o sustento de suas famílias no Brasil. Para:

[...] afirmam que o Brasil é um país multicultural, com influência de diversos fluxos migratórios, grande diversidade linguística, marcado por enormes desigualdades sociais e que, historicamente, desconsiderou a riqueza a cultura popular, negra e dos povos indígenas; enfim dos mais diversos segmentos sociais. Talvez pelo fato de o Canadá ser um país bilíngue, cujo pacto político acordado institucionalmente inclui o multiculturalismo como política nacional, a diversidade na educação tenha sido uma temática mais acentuada nos últimos anos. Acrescentam- se, a isso, discussões que se fazem presentes sobre a necessidade de os indivíduos manterem suas raízes culturais e históricas, cujo centro está na manutenção da língua materna e de elementos representativos das tradições de sua cultura. (NENEVÉ; PROENÇA, 2005, p.8)

Conforme a (REVISTA BRASIL/ CANADÁ, 2013, p.25): O Brasil e o Canadá possuem tantos pontos incomuns, pois o multiculturalismo é algo comum entre os países com um histórico único. Para CARMEN TEREZA VELANGA (2005) defende que: O multiculturalismo é um movimento que ocorre com mais ênfase no Canadá e Brasil, cujo objetivo aparente é a valorização dos diferentes meios formativos étnicos. Ou seja, o ponto de vista referente ao assunto é que: A maneira de aceitar ou rejeitar a diferença de uma cultura e a diversidade racial, levando no zelo de cuidar da pluralidade como aspecto instrumental, podendo todos conviver no mesma área abrangente geográfica. Em decorrência disso (DION, 2003, p.24), transmite que: acredita haver diversos comportamentos culturais relacionados ao trato de passar uma cultura para outra, ou vice e versa. Compreendo que tanto o Brasil como o Canadá integra e atrai estudantes e turistas por meio da Abecan com seus Necs, visando unir o útil com o agradável, aproveitando várias formas para aquecer e fortalecer o mercado econômico do país. Em tempos contemporâneos, de influenciar e incentivar outros países com o essencial intercâmbio no mundo globalizado ser uma forma de expandir e liderar o mercado competitivo, pois seria

\footnotetext{
${ }^{5}$ Maior catástrofe de todo os tempos, o terremoto vitimou muitas famílias daquele país.
} 
como um diferencial competitivo o país sair na frente se destacando. Hoje o Canadá é o país mais acolhedor com mais de 250 mil imigrantes por anos. Então, consta na:

[...] que: a política de multiculturalismo do Canadá é bastante reconhecido internacionalmente. Todo mundo sabe que se trata de um país que dá boas vindas aos estrangeiros. Mas, com a globalização, o tem da diversidade ganha relevância, comenta a professora Walkyria Norte Mór, coordenadora do Núcleo de Estudos das Especialidades na Universidade de São Paulo e do grupo de trabalho "Transculturalidade, linguagem e educação" da Associação Nacional de Pós- Graduação e Linguística. (REVISTA BRASIL/ CANADÁ, 2013, p.26)

Atualmente o Nec em Rondônia possui uma posição muito estratégica na região norte, mais propensão aos investimentos e empreendimentos, influencia a integração das nações por meio da globalização com o multiculturalismo: , o intercâmbio entre as nações multiculturais traz muitos benefícios. O Núcleo de Estudos Canadenses em Rondônia está inserido na Amazônia legal, tem o papel de ampliação da troca de informação, assimilação da informação para gerar conhecimento, como também leva a consolidar ao nível Brasil. O intercâmbio cultural entre Brasil e Canadá. Com isso, hoje o Nec tem uma grande importância para a sociedade, pois com os estudos existentes e desenvolvimentos, alavanca o nome das duas nações envolvidas. De certa forma a autora vai ao encontro do pensamento explicito: (CAVALCANTI, 2004, p.9I) O mundo globalizado sinaliza uma tendência marcante a uma crescente retração do estado. Tem sido evidente a orientação das políticas no sentido da expansão da escolaridade básica, em detrimento da educação superior e, consequentemente, da ciência e da tecnologia. Desde então, o Núcleo tem sido visitado assiduamente por alunos e professores que necessitam da Biblioteca do Núcleo que conta com várias obras sobre o Canadá, e o Brasil, bem como vários outros campos do conhecimento.

O Nec tem também promovido atividades acadêmicas e sociais estimulando os estudantes, principalmente na área do conhecimento de Humanas, a desenvolverem projetos que promovam situações de aprendizagem, contato com outros idiomas, principalmente inglês, francês e espanhol bem como situações de ensino de línguas estrangeiras.

Pode-se afirmar que o Nec ajuda a criar e consolidar um espaço internacional e interdisciplinar muito efetivo na Universidade Federal de Rondônia. A atuação do NEC como promotor de intercâmbio, de conhecimento de outros idiomas, de estímulo a 


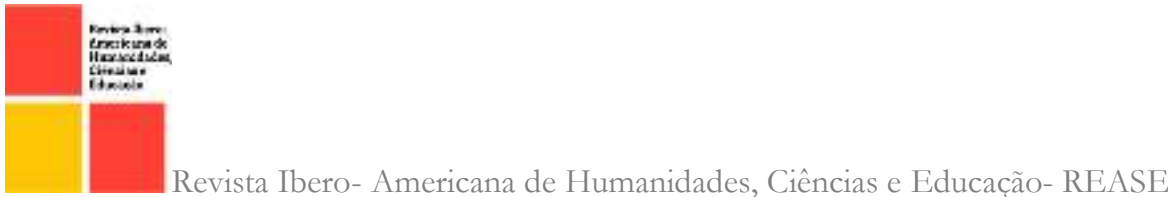

trabalhos de tradução e a questões sociais é inegável. Então, o Núcleo de Estudos canadenses, atende ao público acadêmico e mais especificamente aos graduandos em doutorado e mestrado. A entidade é considerada a maior biblioteca com o maior acervo estrangeiro de línguas estrangeiras de Rondônia. E Sendo uma biblioteca Universitária, elucida o autor com maior precisão: (VERGUEIRA,1989, p.20); A biblioteca universitária deve atender aos objetivos da universidade, a saber, o ensino, a pesquisa e a extensão à comunidade. Dessa maneira, conseguimos evidenciar que chegam da embaixada do Canadá muitas obras que tem a finalidade de disseminar a informação e conhecimentos políticos, econômicos, social e cultural do Canadá. O NEC possui uma variedade de obras editadas no Canadá e estes à primeiro momento do início do projeto se encontravam expostos à luminosidade, empoeirados e desorganizados, fatores que levam a degradação das obras, agora que foi desenvolvido atividades propostas com o intuito de organizá-los e recuperá-los para o uso de pesquisas e projetos acadêmicos que envolvam o Canadá, este que com a ajuda do Canadá e sua Embaixada apoia o Núcleo de Estudos canadenses, com o intercâmbio, projetos e livros doados para promover e incitar à cultura.

2. PROCESSO DE INFLUÊNCIA DA GLOBALIZAÇÃO, MULTICULTURALISMO

Neste tópico, e com base na literatura proposta, analisamos o conceito de globalização, bem como o surgimento do fenômeno do multiculturalismo como conceito e experiência relacionados ao mundo global. Em seguida, discutimos a questão da diversidade cultural e das relações interculturais surgidas a partir da articulação entre multiculturalismo e globalização. (HALL, 2006) O multiculturalismo é algo intrínseco sendo precedido da globalização, processo rápido, integral e real que possui suas relações de integração entre as nações que produzem informações constantemente a cada dia, ou seja, esse comércio internacional impõe regras que torna a ser forçado para cumprir o sistema. Esse multiculturalismo tem representação da mistura relacionada entre as culturas e práticas que leva a composição da cultural social que acaba sendo sua espinha dorsal.

Do mesmo modo, o autor continua sua análise levantando três questões de fundamental importância para a compreensão do processo globalizatório. Com base nestes instrumentos as identidades de seus locais estão se desestruturando devido o aumento exponencial da adaptação dessas misturas de raças culturais que vão se mesclando, essa 


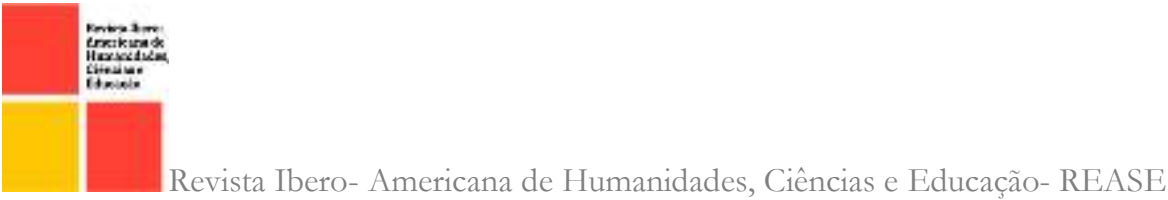

troca cultural que, ao mesmo tempo em que contribui recebe influência. Nesta circunstância, entende-se que esse processo vem desfragmentando, deixando fraca a cultura existente, por força da ação de impor novos formatos de costumes e tradições no núcleo das culturas, contudo essa cultura estabelecida se molda, muitas se mescla ou até pode apagar a identidade com a soma das novas tendências, levando assim ao colapso e enfraquecimento. Nesta conjuntura esses formatos culturais impõem medidas e paradigmas de consumir produtos e serviços de influência de outras nações, hoje é um problema, pois essa exposição a esses modelos deixaram as origens das culturas enfraquecidas e desfragmentadas devido o processo que impera nas nações pobres e desenvolvidas, tudo ocorre pelos meios de comunicação.

Contudo, isso leva a consolidar cada vez essa exposição a esses padrões de nações de origens culturais, fora que as identidades em seu núcleo ficam autoritários que pode ser conhecido pelo termo que conduz como homogeneização cultural das identidades nacionais, será que as origens das culturas desaparecem por meio da homogeneização. Assim (HALL, 2006) explica que, apesar de todo esse contexto podemos compreender que depois da explosão bibliográfica, chamado bom informacional, é uma era da globalização e do multiculturalismo que transcende as barreiras das fronteiras internacionais, nacionais $\mathrm{e}$ as culturas diversas, concretizando o adaptador e o adaptado de culturas sofrer influências no seu interior dos costumes, ritos, superstições e cerimonias, a globalização vem impregnando a hegemonia mediante uma visão predominante econômica.

Nisso vem à tona a tornar o Nec mais aparente para continuar a promover debates, projetos e iniciativas que visa analisar e conceder mais projetos de educação e cidadania inclusiva, ou seja, o Nec é um agente multicultural (o agente bibliotecário como um agente multicultural que tem que promover) que tem o intuito de termos gerais de praticar a difusão e disseminação da informação seja por meios do seu acervo. Por outro lado, necessariamente temos a faca e o queijo na mão, no entanto, o Canadá e o Brasil são países que mais sofrem tendência e imposição do multiculturalismo, pois difundem os valores sociais e multiculturais, a cartada principalmente de Rondônia, é destaque como a preferida do cenário nacional, com a economia consolidada e pujante por meio das exportações nas suas relações internacionais e exteriores tem um mercado muito forte. quem não faz parte desse processo está fora do contexto social e mundial, 
assim como cada vez que corremos atrás suprir os próprios objetivos o tempo passa a ficar mais escasso, em que a cada dia que passa a "sociedade não é a mesma geração da de ontem ou de um tempo atrás”, por que tende a se transformar na medida em que a informação progride, a sociedade também avança. (MARTINS, 2oro, p.7)

Na situação atual, HALL (2006) e PRYSTON (2010) inferem que a globalização é um processo contínuo e deve ser mais discutido. A cultura nacional é baseada na modernidade. Neste caso, a identidade de um país se sobrepõe a outras culturas. Criando um a identidade neste ambiente, além da identidade de possuir sua terra, também introduz mais contrastes culturais. Eu entendo que a globalização trouxe um impacto incomensurável para a sociedade, o indivíduo tem um impacto maior devido à peculiaridade do capitalismo, está intimamente relacionado e inserido nele.

\section{COMO A GLOBALIZAÇÃO MOVE FRONTEIRAS E PROMOVE O MULTICULTURALISMO?}

Os dois autores, HALL (2006) e WILLIAMS (20II) confirmam que o processo de modelo de hibridismo é um modelo que resulta a partir de choques de coalizão e embates culturais, o hibridismo cultural traz novos conceitos e maneiras de entender os significados e enigmas trazidos opostamente às suas matrizes culturais de origem, fato que leva o ser racional a uma crise existencial da identidade do próprio. Entretanto, isso leva a entender a relação de pode e superioridade de uma nação, pode funcionar como uma maneira de conceder mais poder às diversas culturas que elevam a supremacia. Isso tende a levar um embate entre as culturas em relação seja entre o: "Influenciador" e "Influenciada". Será que o resultado da mistura de várias raças inversamente leva a gerar o mestiço, um ser humano que podemos dizer que seria um ser "híbrido" quem nem ocorre com os animais de raças diferentes. No que diz respeito histórico do Brasil e Canadá, podemos perceber serem inteiramente nações conhecidas como as mais multiculturais do mundo, os mesmos países passaram por um processo de colonização, o primeiro foi colonizado por português e o segundo por ingleses e franceses, esses países têm fortalecido sua sociedade com os efeitos dos fluxos migratórios, em que acolhem imigrantes por variadas circunstâncias sociais. Hoje esse nosso mosaico de culturas é mais conhecido popularmente como a nação brasileira que apoia os movimentos das migrações com o incentivo do governo que fomenta a imigração. Existem muitas colônias tanto no sul e no sudeste, o Brasil possui a maior população de japoneses fora do Japão e no sul do país tem muitas colônias que 
possuem muitas colônias: italianas, russa, inglesa, francesa, alemã e entre outras. Diante desses problemas expostos, o país Canadá tem uma política única para gerenciamento do multiculturalismo de propor o desenvolvimento de políticas e ações para criar ou encontrar uma identidade nacional com intuito de zelar pelo respeito, aceitação do outro, exclui o preconceito, proteger a diversidade, conceder politicas de oportunidade e igualdade e integrar as pessoas e suas diversidades culturais com a expectativa de diminuir os isolamentos das minorias. Em primeiro lugar o multiculturalismo ocorre no Nec de forma sistemática, atualmente, possui uma missão e papel importante como agente multicultural, além de realçar e fortalecer cada vez mais a diplomacia do Brasil com o Canadá e suas relações internacionais exteriores que se firmam a cada dia, é por meio do intercâmbio que funciona o ensino e pesquisa interdisciplinar de discentes, professores, pesquisadores e imigrantes que por efeito desse conjunto aprofundam esse conhecimento mutuo que leva para os países, assim existem muitos Necs distribuídos pelo Brasil que contribuem para difundir e levar o conhecimento da sociedade do Canadá e dos demais países para reflexão e discussões teórica multidisciplinar, no momento é visível o quanto o Canadá é um país que entende a nossa importante dimensão diante das relações com diversas regiões do mundo.

Esse tipo humano ignora as fronteiras. No mundo tudo se apresenta a ele em generosa amplitude e, onde quer que se erija um obstáculo a seus propósitos ambiciosos, sabe transformar esse obstáculo em trampolim. Vive dos espaços ilimitados, dos projetos vastos, dos horizontes distantes. (HOLANDA,1995,p.42)

Resenhamos os principais pontos abordados no contexto do NEC, então há um apoio por meio do incentivo por meio e intercâmbio, hoje temos o programa Brasil sem fronteiras e entre outros que apoia a inclusão e o reconhecimento, esse ato de movimento neste mundo globalizado, influencia na transferência que comporta várias tradições e costumes interligado as culturas em seus cenários.

O Brasil com a sua cultura tropical e o Canadá tem um papel preponderante em firmar parcerias para ter uma saudável diplomacia multicultural que pode projetar-se através de diálogos entre diversas localidades dois países mais multiculturais desse planeta, essa conversa dará com a necessidade de entender a realidade do cenário atual do mundo, com certeza que esse consenso político entre poderes pode ocasionar uma abertura de uma sadia e cordial relação internacional para um mundo multicultural. Essa transferência 
entre culturas e povos relacionados a nações diferentes acabam tornando medidas estratégicas de país com políticas multiculturais.

Ou seja, essa expedição diplomática geraria também uma maneira de intensificar as atividades nas Américas, ao mesmo tempo, em que tornava uma interligação de conectar por meio da economia global, isso é beneficial para esses povos que têm uma conexão com os empreendimentos e a cultura do Canadá. Existem muitos debates dos escritores, HALL (2006) e FREYRE (2005) abordam vários termos a respeito dessa interconexão das nações, também relaciona a mistura de raças, que pode conhecer como a mestiçagem e hibridismo e entre vários outros, o individuo pode ter as suas raízes de matrizes em sua diversidade cultural tem um reflexo na adaptação da diversidade regional enfrentada por cada imigrante em cada localidade, ao mesmo tempo, há uma oposição de ideias com os interesses referentes a representação das teorias e a políticas entre a sociedade e a cultura. Percebe que HALL (2006) defende o ser hibrido com duas raças mescladas que obtêm aquisição de cultura por meio da adaptação da cultura de acordo com migrações diante dos fluxos migratórios, imposto a partir de uma política de identidade.

(HALL,2003,p.5o) A formação de uma cultura nacional contribuiu para criar padrões de alfabetização universais, generalizou uma única língua vernácula como o meio dominante de comunicação em toda a nação, criou uma cultura homogênea e manteve instituições culturais nacionais, como por exemplo, um sistema educacional nacional. Dessa forma, a cultura nacional se tornou uma característica- chave da industrialização e um dispositivo da modernidade.

\section{CONSIDERAÇÕES FINAIS}

O objetivo principal deste artigo é relacionar as contribuições de alguns autores, como Stuart Hall, Raymond Williams, Sérgio Buarque de Holanda, Richard Gilberto Freyre, Angela Prysthon. Portanto, produzimos uma breve história do multiculturalismo, demonstrando um crescimento que transcende as barreiras culturais nacionais. Portanto, é necessário mencionar a expansão de diferentes conceitos culturais em todo o processo histórico, a partir do qual podemos perceber as características interdisciplinares do multiculturalismo e da pesquisa cultural, literária e seus objetos e disciplinas. São importantes ressaltar que o conceito: multiculturalismo é muito parecido, e tem significados e finalidades com pontos de vista de muitos autores que serviu de base para o andamento do trabalho, essas fontes primárias tiveram reflexo para às pesquisas. $\mathrm{O}$ Necs 
existe em todo o Brasil propaga como boa referência (inter)nacional que representam reflexões, discussões que permeiam e se sedimentam na expectativa temática do assunto.

Por isso, conduz a destacar qual o papel do NEC na Amazônia, como ocorre o processo dessa entidade multicultural, demonstra como o departamento pode proporcionar o multiculturalismo por meio do intercâmbio Brasil - Canadá, que, ao mesmo tempo desenvolver o mercado exterior que une as nações diante da globalização que melhora ao mesmo tempo, as relações exteriores.

\section{REFERÊNCIAS}

ALMEIDA, Sandra Regina Goulart. Perspectivas transnacionais: perspectives transnationales. 2005.p.145-153

BRANDÃO, Euro. Universidade e transcendência. Curitiba: Editora Universitária Champagnat,1996.p.13-117

CANADART: Revista do Núcleo de Estudos Canadenses. Abecan, Salvador, n.12, p.I-20I, 2004 .

DION, Robert. Estudo das transferências culturais: elementos teóricos. In: DINIZ, Dilma Castelo Branco (Org.). Brasil- Canadá: confrontos literários e culturais. Belo Horizonte: Faculdade de Letras/ABECAN/ NEC/ UFMG, 2003. I7op.

FREYRE, Gilberto. Casa-Grande \& Senzala. 5o ${ }^{a}$ edição. Global Editora. 2005.46rp.

HALL, Stuart. A Identidade cultural na pós-modernidade. Rio de Janeiro: DP\&A, 2006.rozp. .Da diáspora: identidades e mediações culturais. Belo Horizonte: UFMG, 2003.223p.

HOLANDA, Sérgio Buarque de. Raízes do Brasil. 26. ed. São Paulo: Companhia das Letras, $1995.226 \mathrm{p}$.

REVISTA BRASIL/ CANADÁ- Juntando talentos: diversidade cultural caracteriza brasileiros e canadenses. Conhecer e aprender com as diferenças favorece os negócios. São Paulo, ano 8, n.4I, Fev./ Mar. 2013.

REVISTA BRASIL/ CANADÁ- Superação: desafios para a realização de grandes eventos esportivos. O que o Brasil pode aproveitar da experiência canadense. São Paulo, ano 8, n.42, Abr./ Maio 2013.

SOUZA, Marilene Proença Rebello. Movimentos contemporâneos de crítica em psicologia e educação: interfaces: Brasil/ Canadá; NENEVÉ, Miguel. Peter Mc Laren, pós- 
modernismo e pós- modernismo de resistência; DUARTE, Newton. A teoria da atividade como fundamento para pesquisas sobre aprendizagens informais em situações de trabalho no Canadá e para reflexão sobre a educação escolar no Brasil. In: (Org.).Educação e diversidade: interfaces Brasil- Canadá. São Paulo: Casa do Psicólogo, 2005. p.8- 33. VERGUEIRO, W. Desenvolvimento de coleções. São Paulo: Ed.Polis. 1989. p. 20-2I. MARTINS, Pedro Paulo Almeida. O valor da Informação dentro do contexto da globalização. Porto Velho, Out..20Io,v.ı, pı-II. PRYSTHON, Angela. Histórias da teoria: os estudos culturais e as teorias pós-coloniais na América Latina. Revista do Programa de Pós-Graduação em Comunicação e Linguagens. Universidade Tuiuti do Paraná, v. 9, n. I, 2010.

WILLIAMS, Raymond. Cultura. Sao Paulo: Paz e terra.239p. 